\title{
UNIDADE DE ENSINO POTENCIALMENTE SIGNIFICATIVA COM A TEMÁTICA ESTEREOQUÍMICA EM PLANTAS MEDICINAIS: UMA PROPOSTA PARA ENSINO PRESENCIAL OU REMOTO
}

Lara Colvero Rockenbach

Daniele Trajano Raupp

\section{Introdução}

Este trabalho objetiva apresentar um produto educacional desenvolvido no Programa de Mestrado Profissional em Química em Rede Nacional - PROFQUIUFRGS. A proposta de ensino é direcionada para a abordagem dos conceitos de estereoquímica, tendo como base a Teoria da Aprendizagem Significativa e estruturada no formato de uma sequência didática, denominada Unidade de ensino potencialmente significativa (UEPS). Uma UEPS objetiva superar a forte dependência da memorização mecânica e dos exercícios tradicionais que são frequentemente resolvidos sem um entendimento mais profundo, promovendo situações que utilizam os conhecimentos prévios dos alunos como ponto de partida para o ensino de conceitos científicos (MOREIRA, 2011). 
Quando buscamos estabelecer uma relação estreita entre o conhecimento conceitual e as situações da vida diária dos estudantes, utilizamos a contextualização com a potencialidade de tornar questões científicas relevantes, fazendo a ponte entre o conhecimento conceitual e as situações da vida real. A compreensão dessa relação por parte dos alunos pode ter impacto positivo na motivação para aprendizagem (DELIZOICOV; ANGOTTI; PERNAMBUCO, 2002). Assim a contextualização pode ser uma importante estratégia para o ensino de tópicos como estereoquímica, que pertence ao domínio da Química Orgânica, pois, geralmente, a "[...] a química orgânica é introduzida de forma árida para os alunos, que não conseguem relacionar esse conhecimento escolar com suas experiências prévias" (CORREIA; DONNER JR; INFANTE-MALACHIAS, 2008, p. 489)

A justificativa para desenvolver um produto educacional na área de Química Orgânica, para o ensino de estereoisomeria, deve-se ao fato de a estereoquímica ser apontada como um tópico desafiador da Química Orgânica, devido ao nível de abstração para a visualização tridimensional de moléculas e a compreensão da influência da estrutura nas propriedades e reatividade. Portanto, manipular, traduzir e interpretar corretamente essas representações são enormes desafios para a maioria dos alunos. (KOZMA; RUSSELL, 1997) e exigem diversas habilidades cognitivas. Além dos problemas relacionados à visualização, estudos demonstram que problemas da aqui- 
sição e domínio de conceitos que são pré-requisitos também impactam na compreensão e diferenciação dos esterioisômeros (ROCKENBACH, 2020a).

Os estudantes ainda dependem fortemente da memorização mecânica e os exercícios tradicionais são frequentemente resolvidos sem um entendimento mais profundo. Uma combinação de estratégias instrucionais apropriadas e a avaliação correspondente é necessária para mudar a percepção dos alunos sobre seu processo de aprendizagem a longo prazo. (GRAULICH, 2015).

Assim, espera-se que o uso de uma abordagem contextualizada, aliada a uma estratégia de aprendizagem significativa, possa fomentar a compreensão das conexões entre a sociedade e a ciência, contribuindo para despertar o interesse e, consequentemente, a motivação para o aprendizado da temática e dos conceitos de estereoquímica. Ademais, considerando que o conhecimento prévio é o fator que mais influencia a aprendizagem, emprega-se a temática plantas medicinais para o desenvolvimento de um produto educacional, uma vez que há uma estreita relação entre inúmeras plantas medicinais e a estereoquímica. Isso porque inúmeras plantas medicinais contêm compostos químicos que apresentam quiralidade ou diastereoisomeria, moléculas estas que podem ser compreendidas por meio da perspectiva da estereoquímica. (ROCKENBACH et al, 2020b). 
Como resultado, espera-se que essa unidade de ensino além de contribuir para a organização das atividades de ensino e para o aprendizado desse tópico desafiador, possa ser um estímulo para os professores que desejarem adotar essa estratégia com o uso de diferentes temáticas e conceitos científicos. Por fim, diante dos desafios impostos na atualidade devido à pandemia do novo coronavírus, cabe destacar que o produto educacional foi desenvolvido para utilização tanto no ensino presencial quanto no ensino remoto.

\section{Desenvolvimento}

Aprendizagem significativa e o uso de unidades de ensino potencialmente significativa

Considerada como um dos mais importantes aportes cognitivistas, a Teoria da Aprendizagem Significativa, proposta por David Ausubel (AUSUBEL; NOVAK; HANESIAN, 1980; AUSUBEL, 2003), busca analisar como o indivíduo adquire conhecimento e como sua estrutura cognitiva é construída. Sob a ótica ausubeliana, a aprendizagem é um processo por meio do qual uma nova informação interage de forma substantiva (não-literal) e não-arbitrária com subsunçores específicos existentes na estrutura cognitiva do indivíduo. Em outras palavras, a nova informação ancora-se em conceitos ou proposições relevantes já presentes naquela estrutura cognitiva. As- 
sim, pode-se afirmar que há uma forte relação estabelecida entre o aprendizado e o contexto no qual o indivíduo está inserido (RAUPP, 2015).

O impacto do conhecimento prévio, no processo de aprendizagem, é destacado por Ausubel, Novak e Hanesian (1980, p.137) que, ao afirmarem que se tivesse que reduzir toda psicologia educacional a um princípio único, seria: "O fator isolado mais importante que influencia a aprendizagem é aquilo que o aprendiz já conhece. Descubra o que ele sabe e baseie nisso os seus ensinamentos." Isso porque quando o aprendiz interage com o conteúdo de maneira literal, diz-se que sua aprendizagem será mecânica, visto que, de uma forma geral, ficará limitado a reproduzir esse conteúdo de maneira idêntica àquela que lhe foi apresentada. A aprendizagem mecânica se baseia em decorar novas ideias e não a estabelecer conexões e, por isso, trata-se de um aprendizado com menores chances de permanecer na estrutura cognitiva do aluno a longo prazo. No entanto, quando o aprendiz consegue estabelecer conexões entre esse conteúdo novo e o seu conhecimento prévio ocorre a construção de significados pessoais para essa informação. Essa construção de significados não é realizada de forma "literal"; desse modo, se caracteriza como uma aprendizagem significativa (TAVARES, 2004).

Assim, a aprendizagem significativa é considerada, de acordo com Moreira (2010), uma ampliação na 
estrutura cognitiva que opera como âncora para novos conceitos e ideias, estabelecendo relações entre as ideias e organizando-as hierarquicamente. $\mathrm{O}$ (a) professor(a) tem, portanto, como objetivo facilitar a construção dessas relações lógicas, selecionando as ideias básicas e partindo de conhecimentos mais amplos em direção aos mais restritos e específicos (diferenciação progressiva), para depois retornar aos conhecimentos mais amplos ( reconciliação integrativa). A reconciliação integrativa consiste na construção e reconstrução das relações conceituais, visto que novos conceitos foram incorporados à estrutura cognitiva e precisam ser reorganizados. Essa facilitação deve partir dos conhecimentos prévios, sendo estes considerados por Ausubel, Novak e Hanesian (1980) a principal variável a influenciar a aprendizagem significativa.

Unidades de Ensino Potencialmente Significativas (UEPS)

Moreira (2011) propõe a criação de materiais potencialmente significativos, com uma boa estrutura e desencadeamento lógico (coerência de argumentos) e, ainda, que façam sentido ao grupo ao qual se pretende apresentar determinado conteúdo e que contribuam para um aprendizado de maior qualidade, que se distancie do aprendizado mecânico, com o objetivo de facilitar a construção de relações lógicas entre os conceitos abordados. Esse material é organizado em Unidades de Ensino Po- 
tencialmente Significativas (UEPS) que, conforme Moreira (2011), são sequências de ensino fundamentadas em teorias pertinentes, que objetivam a aprendizagem significativa, em oposição à aprendizagem mecânica. Tem como foco promover uma modificação no ensino que, ao longo das décadas, foi pautado na memorização de conteúdo, causando apenas uma aprendizagem memorística a partir de Unidades de Ensino Potencialmente Facilitadoras para a aprendizagem de determinados tópicos. (MOREIRA, 2011).

A proposta da construção de uma UEPS segue, de forma geral, essas etapas, mas pode ser adaptada conforme o critério do docente. Tais etapas estão explicadas abaixo, sob a luz do trabalho de Schittler e Moreira (2014):

1) Situação inicial: Nesta etapa deve-se propor situações buscando que o aluno revele seus conhecimentos prévios em relação ao conteúdo, podendo estes serem ou não aceitos no contexto de ensino. Esta situação pode se basear em discussões, questionários, mapas conceituais ou podem ser a própria situação problema proposta.

2) Situação-problema inicial: Tendo em mãos os conhecimentos prévios dos alunos, deve-se propor uma situação-problema de nível introdutório, envolvendo os assuntos a serem estudados, buscando dar um sentido à temática. Podem ser propostas situações por meio de si- 
mulações computacionais, demonstrações, vídeos, problemas, matérias midiáticas, exercícios clássicos da matéria, buscando ter um nível acessível e problematizador.

3) Aprofundamento do conhecimento: O conhecimento deve ser apresentado a partir da diferenciação progressiva, partindo-se de aspectos mais gerais, com uma visão integrada dos elementos relevantes à matéria de ensino para a exemplificação de pormenores específicos. Como estratégias de ensino deve-se valorizar atividades colaborativas após exposição do conteúdo, como atividades em grupos e apresentações. Conceitos estruturantes devem ser apresentados em níveis crescentes de complexidade, sempre destacando semelhanças e diferenças entre os exemplos, em uma reconciliação integradora.

4) Nova situação-problema: Acompanhando a lógica da UEPS, a nova situação problema deve propor questionamentos com um nível de profundidade maior, evidenciando as correspondências e contradições entre os conceitos. As atividades propostas devem valorizar ações colaborativas entre os alunos, levando a maior interação e possibilitando a negociação de significados. Como exemplos os autores trazem a resolução de problemas, a construção de mapas conceituais, experimentos de laboratório, projetos, em grupos e com a mediação do professor. 
5) Avaliação somativa individual: A avaliação individual deve ter um caráter processual, comparando as respostas às situações problemas, buscando evidenciar a captação de significados e a capacidade de transferência dos saberes. Além das respostas obtidas por meio das situações problemas, o aluno também é avaliado a partir das anotações do professor relativos à cada etapa de ensino.

6) Aula integradora final: Aborda-se aqui as características mais relevantes do conteúdo em questão, dando continuidade ao método de diferenciação progressiva a partir de uma ótica integradora, buscando a reconciliação integrativa entre os conceitos. Pode ser realizada a partir de uma exposição oral, leitura de texto, recursos computacionais ou audiovisuais, sendo substancial o modo de trabalhar o conteúdo.

7) Avaliação da aprendizagem na UEPS: Uma nova situação problema deve ser proposta ao final da atividade, buscando um nível maior de complexidade em relação às anteriores valorizando sempre a proposição de atividades colaborativas, que devem ser apresentadas ao grande grupo com a mediação do professor. Esta nova atividade avaliativa deve buscar evidências de compreensão de significados e capacidade de transferência do conhecimento para diferentes situações. 
8) Avaliação da própria UEPS: A fim de aprimorar e/ou validar as estratégias de ensino, além da evolução conceitual dos alunos, deve ser considerada uma avaliação conjunta sobre a Unidade de Ensino. Esta avaliação pode se dar por meio de uma roda de conversa, ou mesmo um questionário avaliativo.

Propõe-se neste texto, uma Unidade de Ensino Potencialmente Significativa que associe os conhecimentos e experiências que os estudantes tenham a respeito das Plantas Medicinais à existência de moléculas que atuam como princípios ativos e à compreensão de conteúdos sobre a estereoisomeria a partir de exemplos de estereoisômeros encontrados em tais princípios ativos.

Estereoquímica em plantas medicinais

A estereoquímica é a área da Química que estuda os aspectos tridimensionais das moléculas. Os estereoisômeros, conforme McMurry (2011), são moléculas de idêntica fórmula molecular e conectividade (ordem dos átomos ligados), mas que possuem diferentes configurações (estruturas espaciais). Podem ser classificados como diastereoisômeros, caso das estruturas que não guardam relação enantiomérica, e como enantiômeros, estruturas que não possuem eixo de simetria e existem aos pares (R/S) por possuírem relação especular entre si. Entre os diastereoisômeros, selecionamos neste trabalho os isô- 
meros geométricos $\mathrm{E} / \mathrm{Z}$ ou cis/trans de carbonos de ligações duplas.

Para facilitar essa conexão no campo da estereoquímica há inúmeras temáticas que podem utilizadas, desde os exemplos mais simples, como o caso da gordura trans, ou o mias utilizado que é o caso da talidomida, até exemplos mais complexo, como a interação biológica de determinados fármacos quirais,

(BARREIRO; FERREIRA; COSTA, 1997). Outros exemplos de temas podem ser utilizados, aumentando o repertório de conhecimento dos alunos sobre a utilidade do conceito, o que o torna significativo (RAUPP, PROCHNOW; DEL PINO, 2020). O conhecimento é considerado significativo quando se relaciona com a estrutura cognitiva do indivíduo, tendo maiores chances de permanecer a longo prazo nessa estrutura, em relação à aprendizagem mecânica (MOREIRA, 2010). Existem inúmeros exemplos da ocorrência de estereoisomeria em princípios ativos de plantas medicinais que durante um longo período foram o recurso terapêutico predominante na sociedade. As plantas medicinais atualmente são utilizadas in natura e como a matéria-prima de fármacos sintéticos. (SIMÕES; SCHENKEL, 2000). Considera-se planta medicinal toda espécie vegetal, cultivada ou não, utilizada com propósitos terapêuticos e/ou profiláticos. (BRASIL, 2011).

Largamente utilizadas, as plantas medicinais, segundo a Organização Mundial da Saúde, são utilizadas 
por $85 \%$ da população dos países em desenvolvimento (SOUZA et al, 2013). Inclusive, no Brasil, o Ministério da Saúde publicou em 2006 a Politica Nacional de Plantas Medicinais e Fitoterápicos, que objetiva garantir à população brasileira o acesso seguro e o uso racional de plantas medicinais e fitoterápicos. Os fitoterápicos são obtidos de matéria-prima ativa vegetal, exceto substancias isoladas, com finalidade profilática, curativa ou paliativa, incluindo medicamento fitoterápico e produto tradicional fitoterápico, podendo ser simples, quando o ativo é proveniente de uma única espécie vegetal medicinal, ou composto, quando o ativo é proveniente de mais de uma espécie vegetal. (BRASIL, 2011).

A Química Orgânica teve seu estudo impulsionado pelo uso das plantas na síntese de fármacos como é o caso da síntese do acido acetil salicílico. Sua obtenção foi inspirada nas propriedades de um anti-inflamatório obtido da casca do salgueiro: a salicilina, cujo composto ativo é Salix alba L. Alguns exemplos de princípios ativos de plantas medicinais que podem ser utilizados para contextualização são brevemente citados nos Quadro 1, sendo os dois primeiros exemplos pares de diasteroisômeros (isômeros cis/trans ou $E / Z$ ) e os demais pares de enantiômeros ( compostos com pelo menos um carbono quiral). 
Quadro 1: Estereoisômeros em plantas medicinais

\begin{tabular}{|c|c|c|c|}
\hline $\begin{array}{c}\text { Plantas } \\
\text { Medicinais }\end{array}$ & $\begin{array}{c}\text { Fórmula dos isôme- } \\
\text { ros }\end{array}$ & $\begin{array}{l}\text { Atividades } \\
\text { Biológicas }\end{array}$ & $\begin{array}{c}\text { Características dos } \\
\text { Isômeros }\end{array}$ \\
\hline $\begin{array}{c}\text { Erva doce } \\
\text { (Pimpinella } \\
\text { anisum),anis } \\
\text { estrelado, } \\
\text { funcho, } \\
\text { (CARAMORI, } \\
\text { 2009). }\end{array}$ & Anetol & $\begin{array}{l}\text { Antimicrobi- } \\
\text { ana e analgé- } \\
\text { sica (PINTO, } \\
\text { 2018) }\end{array}$ & $\begin{array}{c}\text { Isômero cis apresenta } \\
\text { alta toxicidade e } \\
\text { propriedades orga- } \\
\text { nolépticas desagradá- } \\
\text { veis (PAZINI, 2013). } \\
\text { Nome IUPAC: } E, Z \\
\text { metóxi-4-prop-1- } \\
\text { enilbenzeno. }\end{array}$ \\
\hline $\begin{array}{c}\text { Canela (Cin- } \\
\text { namomum } \\
\text { zeylanicum) } \\
\text { (MONTEIRO, } \\
\text { 2013). }\end{array}$ & $E, Z$ - Cinamaldeído & $\begin{array}{l}\text { Antimicrobi- } \\
\text { ana e antiin- } \\
\text { flamatória } \\
\text { (FIGUEIRED } \\
\text { O, 2017) }\end{array}$ & $\begin{array}{l}\text { O produto presen- } \\
\text { te na natureza é o } \\
E \text { - cinamaldeído. } \\
\text { Nome } \\
\text { IUPAC:fenilprop- } \\
\text { 2-enal. }\end{array}$ \\
\hline $\begin{array}{c}\text { Capim santo } \\
\text { (Cymbopogon } \\
\text { citratus) } \\
\text { cidreira } \\
\text { (Lippia alba) } \\
\text { (MORAIS, } \\
\text { 2009). }\end{array}$ & $R, S$ - Limoneno & $\begin{array}{c}\text { Ansiolítico } \\
\text { (SILVA, } \\
\text { 2011) }\end{array}$ & $\begin{array}{c}\text { O isômero R apre- } \\
\text { senta odor de limão } \\
\text { e o isômero S apre- } \\
\text { senta atividade } \\
\text { inseticida e odor de } \\
\text { fruta cítrica, princi- } \\
\text { palmente de laranja. } \\
\text { Nome IUPAC: 1- } \\
\text { metil-4-(prop-1-en- } \\
\text { 2-il)ciclo hex-1-eno). }\end{array}$ \\
\hline
\end{tabular}




\begin{tabular}{|c|c|c|c|}
\hline $\begin{array}{c}\text { Cidreira } \\
\text { (Lippia alba) } \\
\text { (MORAIS, } \\
\text { 2009) } \\
\text { Hortelã ( } \\
\text { Mentha spica- } \\
\text { ta) e cominho } \\
\text { (Carum carvi } \\
\text { L) (PINTO, } \\
\text { 2014). }\end{array}$ & $R, S$ - Carvona & $\begin{array}{c}\text { Efeitos no } \\
\text { sistema } \\
\text { nervoso } \\
\text { central, } \\
\text { antibacteria- } \\
\text { na, anticon- } \\
\text { vulsionante, } \\
\text { citotoxicida- } \\
\text { de em células } \\
\text { cancerígenas, } \\
\text { antifúngica e } \\
\text { carminativa. } \\
\text { (PINTO, } \\
\text { 2014) }\end{array}$ & $\begin{array}{l}\text { A } R \text {-carvona é extra- } \\
\text { ída da hortelã , sendo } \\
\text { o seu maior consti- } \\
\text { tuinte. Já a } S \text {-carvona } \\
\text { é o maior constituin- } \\
\text { te de plantas como o } \\
\text { cominho (PINTO, } \\
\text { 2014). } \\
\text { Nome IUPAC: } R, S \text { - } \\
\text { 2-metil-5-(prop-1- } \\
\text { en-2-il)ciclohex-2- } \\
\text { en-1-ona. }\end{array}$ \\
\hline $\begin{array}{l}\text { Eucalyptus, } \\
\text { erva- cidreira } \\
\text { (Melissa } \\
\text { officinalis), } \\
\text { menta (mentha } \\
\text { L.), canela } \\
\text { (cinnamo- } \\
\text { mum), capim } \\
\text { santo (cymbo- } \\
\text { pogon) } \\
\text { (OLIVEIRA, } \\
\text { 2016). }\end{array}$ & $\overbrace{R, S \text { - Citronelal }}$ & $\begin{array}{l}\text { Antifúngico } \\
\text { e Antioxi- } \\
\text { dante } \\
\text { (OLIVEIRA, } \\
\text { 2016) }\end{array}$ & $\begin{array}{l}\text { A estereoisomeria } \\
\text { não interfere nas } \\
\text { atividades antifúngi- } \\
\text { ca e antioxidante, } \\
\text { bem como na citoto- } \\
\text { xidade dos compos- } \\
\text { tos. (OLIVEIRA, } \\
\text { 2016). } \\
\text { Nome IUPAC: } 3,7- \\
\text { dimetiloct-6-en-1-al. }\end{array}$ \\
\hline
\end{tabular}

Fonte: Autoras

A Unidade de Ensino Potencialmente Significativa pro-
posta

Visando contribuir com o ensino dos tópicos relacionados à estereoquímica, organizou-se uma sequência didática (Quadro 2) com abordagem contextualizada. A 
contextualização no ensino de ciências visa constituir conexões entre a sociedade e a ciência, de forma que os conceitos científicos abordados tenham relevância para o entendimento de situações do cotidiano (KRASILCHIK, 2000). Aqui a proposta utiliza de cinco aulas, sendo dois momentos distintos de aprofundamento do conteúdo e avaliação somativa individual, um para cada tipo de estereoisomeria.

Quadro 2: Síntese UEPS - Estereoisômeros em Plantas Medicinais

\begin{tabular}{|c|c|c|}
\hline Sequência & Etapa da UEPS & Estratégia/ Recursos utilizados \\
\hline Aula 1 & $\begin{array}{l}\text { Apresentação da } \\
\text { Proposta de UEPS } \\
\text { Situação Inicial }\end{array}$ & $\begin{array}{l}\text { Questionário investigativo a respeito } \\
\text { dos hábitos e conhecimento em } \\
\text { relação à temática. } \\
\text { Discussão do Documentário "Nem } \\
\text { Santas nem do Diabo: O Potencial } \\
\text { Inexplorado das Plantas Medicinais". }\end{array}$ \\
\hline Aula 2 & $\begin{array}{l}\text { Situação-problema } \\
\text { inicial } \\
\text { Aprofundamento do } \\
\text { conteúdo: isômeros } \\
\text { cis-trans, } E, Z \\
\text { Avaliação formativa }\end{array}$ & $\begin{array}{l}\text { Formulário para Interpretação de } \\
\text { fórmulas estruturais em traços de } \\
\text { pares de diastereoisômeros presen- } \\
\text { tes em plantas. } \\
\text { Exposição teórica do conteúdo com } \\
\text { auxílio de slides e modelos molecu- } \\
\text { lares. } \\
\text { Formulário para nova interpretação } \\
\text { das estruturas simplificadas. }\end{array}$ \\
\hline
\end{tabular}




\begin{tabular}{|c|c|c|}
\hline Aula 3 & $\begin{array}{l}\text { Nova situação- } \\
\text { problema inicial }\end{array}$ & $\begin{array}{l}\text { Formulário para interpretação de } \\
\text { fórmulas estruturais simplificadas de } \\
\text { pares de enantiômeros presentes } \\
\text { em Plantas Medicinais. } \\
\text { Exposição teórica do conteúdo com } \\
\text { auxílio de slides e modelos molecu- } \\
\text { lares. } \\
\text { Montagem e visualização das molé- } \\
\text { culas em 3D, no aplicativo "Molecu- } \\
\text { lar Constructor". }\end{array}$ \\
\hline Aula 4 & $\begin{array}{l}\text { Aula integradora final } \\
\text { Avaliação de aprendi- } \\
\text { zagem na UEPS }\end{array}$ & $\begin{array}{l}\text { Síntese das temáticas, modelos e } \\
\text { conceitos, elaborados na UEPS com } \\
\text { auxílio de slides e modelos molecu- } \\
\text { lares. } \\
\text { Elaboração de mapa conceitual. }\end{array}$ \\
\hline Aula 5 & $\begin{array}{l}\text { Avaliação somativa } \\
\text { Individual } \\
\text { Avaliação da própria } \\
\text { UEPS }\end{array}$ & $\begin{array}{l}\text { Avaliação tipo teste com exercícios } \\
\text { de/ou adaptados de processos } \\
\text { seletivos. } \\
\text { Aplicação de questionário. }\end{array}$ \\
\hline
\end{tabular}

Fonte: Autoras

As etapas da Unidade de Ensino Potencialmente Significativa proposta estão descritas a seguir, cada uma conta com um objetivo específico, elaborado de acordo com Schittler e Moreira (2014). 
Apresentação da Proposta de UEPS

Nessa etapa o objetivo é investigar hábitos e conhecimentos a respeito da utilização das Plantas Medicinais no cotidiano dos estudantes, buscando possíveis subsunçores ou a necessidade do uso de organizadores prévios. Com uso de um questionário investigativo busca realizar um levantamento dos conhecimentos, crenças, sentimentos, valores, interesses e experiências dos estudantes perante a temática e busca informações sobre os conhecimentos prévios dos alunos, a fim de considerá-los durante a busca de subsunçores ou âncoras para a Aprendizagem Significativa. A seguir, no Quadro 3, as questões propostas.

Quadro 3: Questionário Investigativo

\section{Questões Elaboradas para Questionário Inicial}

1) Em seu ambiente familiar vocês costumam utilizar plantas com a finalidade de tratar sintomas e/ou problemas de saúde?

$\square$ Nunca $\quad \square$ Raramente $\quad \square$ Às vezes $\quad \square$ Muitas Vezes

$\square$ Sempre

2) Em seu ambiente familiar vocês costumam comprar medicamentos fitoterápicos (à base de plantas)?

$\square$ Nunca $\quad \square$ Raramente $\quad \square$ Às vezes $\quad \square$ Muitas Vezes

$\square$ Sempre

3) Você considera plantas medicinais como fontes confiáveis de tratamentos de saúde?

$\square$ Não considero $\quad \square$ Considero em Parte $\quad \square$ Considero

$\square$ Outro, justifique

4) Entre as plantas abaixo, assinale aquelas que você conhece e/ou 
já utilizou e descreva sua utilidade para a saúde:

。Capim Limão, 。 Erva Cidreira, 。 Erva Doce, 。 Anis Estrelado, - Canela, - Cravo,

-Boldo, 。Hortelã, 。Eucalipto, 。 Limão/Laranja,

- Lavanda, 。 Manjericão

5) Você conhece alguém que se ocupe cultivando, preparando ou indicando o uso de plantas medicinais?

6) Sobre a pergunta 5), explique, comente ou relate o que esta pessoa faz:

7) Na sua opinião, qual a relação entre os conhecimentos científicos, químicos e farmacológicos e os saberes populares relacionados às plantas medicinais?

Fonte: Autoras.

Situação inicial:

O objetivo da utilização de um documentário é introduzir a temática de maneira ampla, com alto nível de generalidade, explorando aspectos naturais e sociais que levem o aluno a expressar seu conhecimento prévio no contexto da matéria de ensino. Após a aplicação do questionário, pode-se realizar a apresentação do documentário, ou de trechos do documentário, disponibilizado pela Unifesp - Universidade Federal de São Paulo: "Nem santas nem do diabo: o potencial inexplorado das plantas medicinais", disponível no Youtube. O documentário foi selecionado por apresentar múltiplas abordagens da temática das plantas medicinais no contexto brasileiro, como: a pesquisa em sociobiodiversidade, os cuidados no 
uso das plantas, o debate sobre saberes tradicionais e científicos e o potencial da indústria farmacêutica das plantas medicinais. Após a apresentação do documentário, um pequeno debate deve ser suscitado, podendo partir dos principais conceitos abordados no vídeo.

Situação-problema inicial:

Essa situação deve introduzir o tópico a ser ensinado (diasteroisomeria), problematizando os novos conhecimentos. A situação problema inicial ( Figura 1) pode ser realizada por meio do Google formulários, de maneira síncrona, delimitando-se um tempo de cerca de 20 minutos para resolução. É muito importante que os alunos percebam a importância desta exploração inicial, para isso, indicamos que durante os 10 primeiros minutos da atividade seja provocada, via plataforma de reunião online, um debate desses conhecimentos prévios, levando os alunos a perceberem os diferentes pontos de vista e saberes uns dos outros, bem como a uma possível negociação destes saberes; para então nos 10 minutos restantes, concluírem a sua resposta no formulário. A finalidade da situação-problema inicial é de verificar se os estudantes conseguem evidenciar semelhanças e diferenças entre fórmulas estruturais de isômeros cis/trans, a partir do exemplo das moléculas isômeras do citral, presente no capim limão e na erva cidreira. Nessa etapa o objetivo é despertar o interesse do aluno em interpretar cientifica- 
mente as estruturas e atividades biológicas dos diastereoisômeros, motivando a investigação de conceitos e proposições à respeito da temática. Busca-se também verificar quais habilidades o aluno possui no que tange à interpretação das estruturas representadas em $2 \mathrm{D}$, por meio da fórmula de traços. Foram apresentadas as imagens das plantas medicinais capim limão e erva cidreira, suas características e propriedades e a representação da estrutura dos isômeros do citral: geranial e neral, (2E)-3,7dimetilocta-2,6-dienal e (2Z)- 3,7-dimetilocta-2,6-dienal; que possuem atividade antiinflamatória e ansiolítica.

Figura 1: Situação problema inicial

Observe as moléculas representadas abaixo, bem como suas diferentes propriedades e descreva o que diferencia as duas * moléculas, a ponto de levar às diferentes caracteristicas.

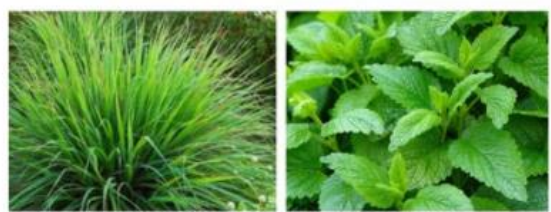

Capim limão e Erva cidreira
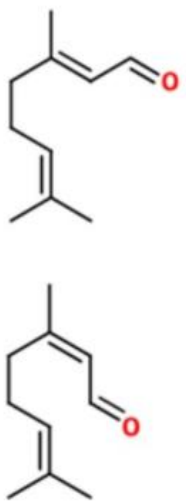

Os isômeros do citral, chamados geranial e neral, estão presentes em plantas como capim santo (Cymbopogon citratus) e cidreira (Lippia alba) (MORAIS, 2009).

Tais moléculas possuem efeitos Anti-inflamatório (LIAO, 2015) e Ansiolitico (SILVA, 2011).

$\mathrm{O}$ Isômero Neral apresenta maior efeito antiinflamatório (LIAO, 2015)

Fonte: Autoras 
Aprofundamento do conteúdo:

O objetivo nessa etapa é apresentar os conceitos científicos, iniciando com aspectos mais gerais, e, em seguida, abordar aspectos específicos (diferenciação progressiva). Para essa etapa, planeja-se uma aula expositiva, contextualizando a estereoisomeria e as plantas medicinais, quais as possibilidades de ocorrência e apresentando os sistemas de nomenclatura. Sugere-se o auxílio de slides e modelos moleculares concretos como, por exemplo, kits de modelos, para assim contribuir com a construção dos conhecimentos científicos a respeito da isomeria, a compreensão dos sistemas de nomenclatura cis/trans e $E / Z$, buscando o desenvolvimento de habilidades representacionais e a identificação dos isômeros.

Avaliação formativa:

Visando analisar a diferenciação progressiva e a reconciliação integrativa dos principais conceitos trabalhados, é necessário relacioná-los a novos exemplos. Dessa forma alunos são novamente convidados a interpretarem fórmulas estruturais simplificadas de diastereoisômeros/isômeros geométricos, presentes em plantas medicinais (Figura 2) diferentes das fórmulas utilizadas na situação problema inicial. Nesta nova situação problema pode-se identificar a reconciliação integrativa, percebendo a habilidade dos alunos em identificar agora as estru- 
turas de acordo com o sistema de nomenclatura $E / Z$, e cis/trans, verificando assim a construção dos conceitos sobre isômeros geométricos e suas nomenclaturas, e a capacidade de interpretar fórmulas em $2 \mathrm{D}$.

Figura 2: Nova Situação Problema 1 - Avaliação Somativa

Diastereoisômeros

Como se diferenciam as moléculas constituintes do eugenol, representadas abaixo? Explique. *
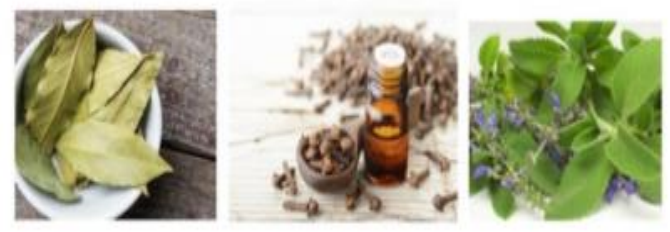

\section{Louro, Cravo e Boldo}

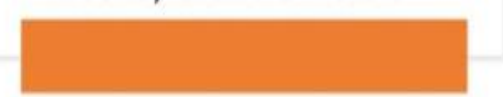

0 eugenol é um principio ativo com atividades Antioxidante (MORAIS, 2009)

Analgésica e Antimicrobiana utilizado em tratamentos dentários, estimulante cardiaco, digestivo, respiratório e antiespasmódico (TANGERINO, 2006).

Faz parte da composiçẵo do boldo ( Pneumus boldus), canela (Cinnamonum zeylanicum), cravo (Eugenia aromatica) e louro (Laurus nobilis L) ( MORAIS, 2009).

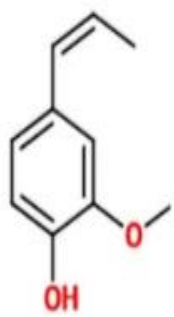

Altas concentrações causam efeitos neurotóxicos, a mistura dos isômeros possui as propriedades citadas (TANGERINO, 2006)

Fonte: Autoras (2020).

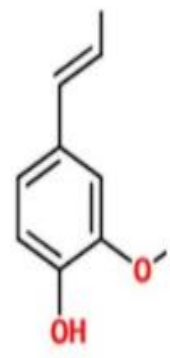


Nova situação-problema:

O objetivo agora é introduzir novos conhecimentos sobre o tópico enantiomeria, relacionando-o aos conceitos já trabalhados, contribuindo com a busca por novos conceitos pertencentes à matéria de ensino estereoisomeria, e incitando a subordinação correlativa, onde há alargamento da estrutura cognitiva do aluno no que diz respeito à temática, ao repetir os processos de diferenciação progressiva e reconciliação integrativa entre os conhecimentos prévios e os novos conhecimentos.

O trabalho com as situações problema, bem como com as avaliações formativas será mais profícuo ao ser realizado na forma de atividades colaborativas, que possibilitam o intercâmbio e a negociação de saberes, sendo a proposta original que o trabalho fosse todo realizado em duplas e presencialmente. No entanto, para o contexto remoto, as atividades podem ser realizadas de forma adaptada, sendo que em ambas as situações o docente deve adotar a postura de mediador das atividades, promovendo a participação ativa dos discentes. Uma possibilidade metodológica para mediar as relações entre o novo conhecimento e os subsunçores já presentes na estrutura cognitiva dos alunos é iniciar cada atividade expositiva do conteúdo retomando o que foi proposto pelos alunos ao responder o formulário, evidenciando os conceitos aceitos na matéria de ensino e diferenciando dos conhecimentos prévios não concernentes com a matéria. 
O formulário proposto pode conter a imagem da estrutura em traços de dois enantiômeros (isômeros ópticos), bem como de plantas medicinais com ocorrência de tais moléculas e suas atividades biológicas, com a finalidade de indicar semelhanças e diferenças entre as estruturas moleculares, a exemplo do demonstrado na Figura 3, como também a reflexão sobre as diferentes atividades biológicas, em um processo de diferenciação progressiva e de reconciliação integrativa.

Segundo Moreira (2011) as situações-problema devem ser propostas em níveis crescentes de complexidade, evidenciando novos significados e diferenciando os subsunçores. Esse novo caso de estereoisomeria é importante para compreender as semelhanças e diferenças relativas às situações e exemplos de diastereoisomeria já trabalhados, agora com a necessidade de interpretar as estruturas em 3D. 
Figura 3: Nova Situação Problema

Observando as moléculas abaixo, de acordo com sua estrutura e fórmula molecular, você considera que são as mesmas moléculas? Qual a diferença entre elas? Discorra. *

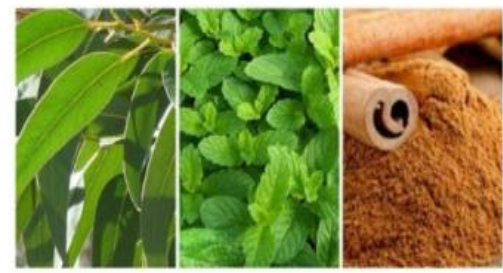

Eucalipto, Menta e Canela

O citronelal apresenta atividades Antifúngica e Antioxidante, e está presente no eucalipto (Eucalyptus), erva- cidreira (Melissa officinalis), menta (mentha L.), canela (cinnamomum) e no capim santo (cymbopogon).

A estereoisomeria não interfere nas atividades antifüngica e antioxidante, bem como na citotoxidade dos compostos. (OLIVEIRA, 2016)
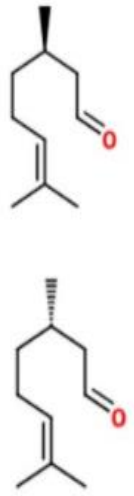

Fonte: Autoras

Dessa forma a diferenciação progressiva poderá promover a incorporação ao subsunçor estrutura molecular, não só os significados relativos a diastereoisomeria, mas também de enantiomeria. $\mathrm{O}$ processo de diferenciação progressiva é concomitante ao processo de reconciliação integrativa, uma vez que permite relacionar as diferentes aplicações de determinados subsunçores na medida em que integra seus significados, enriquecendo a estrutura cognitiva do aprendiz. 
Aprofundamento do conteúdo:

Objetivando promover uma ampliação na estrutura cognitiva do aluno, dar novos exemplos, destacar semelhanças e diferenças em relação às situações e exemplos anteriores, desenvolve-se uma segunda aula expositiva contextualizando a estereoisomeria e as plantas medicinais e abordando a enantiomeria utilizando como recursos didáticos slides e modelos moleculares, a fim de contribuir para o desenvolvimento de habilidades representacionais em 3D. Realiza-se portanto, sucessivas interações entre os subsunçores, retomando a relação entre sistema de nomenclatura, estrutura molecular e atividade biológica, incorporando novos conceitos como quiralidade, propriedades ópticas, modelo chavefechadura, e habilidades de visualização e representação em 3D. Buscando possibilitar assim o desenvolvimento das principais habilidades citadas por Graulich (2015) para o aprendizado da Química Orgânica: habilidades representacionais, visualização espacial e raciocínio científico. Cabe destacar que isomeria óptica e isomeria geométrica são considerados termos obsoletos e com o uso fortemente desencorajado pela IUPAC. Os termos a serem utilizados são diastereoisômeros e enantiômeros. Os enantiômeros são pares moleculares que são imagens especulares uma da outra e não sobreponíveis. Já os diastereoisômeros não têm relação com a imagem especular (McNAUGHT et al 2019). No entanto, é comum encon- 
trar os termos obsoletos em materiais didáticos atuais; por isso, recomenda-se a utilização de ambos os termos.

Avaliação formativa:

Para evidenciar a construção de significados de mais elevado nível de complexidade, em relação às representações tridimensionais, sugere-se uma atividade colaborativa com a mediação do professor. As estruturas enantioméricas da carvona, do limoneno e do mentol, podem ser disponibilizadas, e divididas para o trabalho em dupla. Cada dupla fica responsável pela montagem e visualização de um par de enantiômeros em $3 \mathrm{D}$, no aplicativo gratuito de celular "Molecular Constructor" (Figura 4).

Figura 4: Imagem do aplicativo Molecular Constructor

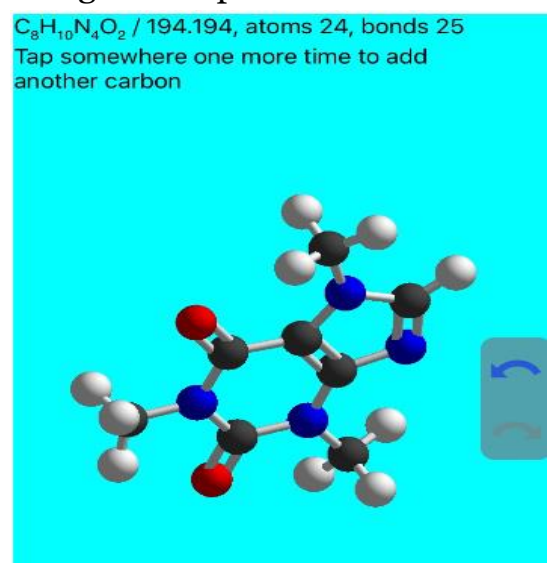

Fonte: Autoras 
Nessa etapa, conforme critério do professor, pode ainda ser utilizado outro aplicativo ou software como o Chemsketch ou construção de modelos com kit ou materiais alternativos. A utilização de modelos concretos, ilustrações, animações, modelagem e simulações podem auxiliar nas dificuldades que os estudantes possuem em visualizar estruturas moleculares em $3 \mathrm{D}$, promovendo a denominada alfabetização tridimensional (RAUPP, 2015). A resolução de problemas em $3 \mathrm{D}$ pode ser facilitada com o uso de modelos e imagens de aplicativos, sendo este tipo de problema um dos principais no estudo da Química Orgânica (FROMM, 1945; SHINE, 1957; EVANS, 1963; HABRAKEN, 1996; WU; SHAH, 2004).

Aula integradora final:

Visando realizar uma síntese das temáticas, modelos e conceitos, elaborados na UEPS, nessa aula retoma-se todo o conteúdo da UEPS, buscando promover a reconciliação integrativa, mostrando a convergência entre os conceitos abordados, revendo as atividades e retornando ao alunos avaliações formativas. Como atividade formativa integradora sugere-se a construção de um mapa conceitual como forma de verificar a ocorrência de processos de diferenciação progressiva e reconciliação integradora levando o aluno a criar e recriar relações conceituais de modo a integrar os significados emergentes de modo harmonioso com os demais (MOREIRA,1988). A 
construção de mapas conceituais como atividade colaborativa pode ser realizada em pequenos grupos de dois a quatro participantes.

Utilizando o mapa conceitual como uma ferramenta, o aprendiz pode organizar seu conhecimento, evidenciando as relações entre os conceitos prévios e os novos conceitos, em um processo de diferenciação progressiva, e interelacionando os novos subsunçores em um processo de reconciliação integrativa. Com a avaliação dos mapas construídos a professora, ou o professor, pode inferir importantes informações sobre possíveis lacunas no material didático utilizado, ou ainda lacunas no aprendizado do estudante, que podem ser sanadas em um momento posterior, e possibilitando também, ao professor, a compreensão de aspectos da estrutura cognitiva de seus estudantes durante a aprendizagem daqueles conceitos. (CORREIA; DONNER JR; INFANTE-MALAQUIAS, 2008; AQUINO; CHIARO, 2013; LIMA; ET AL, 2017)

Avaliação de aprendizagem na UEPS:

Com o objetivo de fornecer evidências da construção de saberes significativos, envolvendo a temática bem como os conceitos e habilidades com relação à estereoisomeria, a avaliação na perspectiva da aprendizagem significativa é realizada do ponto de vista processual e, por isso, feita a partir dos registros das avaliações forma- 
tivas, desenvolvidas ao longo da UEPS e de avaliações ao final da aplicação da mesma. Além da construção do mapa conceitual, como avaliação final, recomenda-se uma avaliação somativa individual na forma de teste para avaliar o alcance de determinados objetivos de aprendizagem.

Avaliação da UEPS:

Pode-se aplicar um questionário individual, com questões do tipo escala Likert (Quadro 4) e também questões abertas, para a avaliação em relação à UEPS da parte dos alunos.

Quadro 4: Questionário final - Questões escala Likert

\begin{tabular}{|l|l|l|l|l|l|}
\hline \multirow{2}{*}{ Questões } & \multicolumn{4}{|c|}{ Nível de concordância } \\
\cline { 2 - 6 } & CF & C & I & D & DF \\
\hline $\begin{array}{l}\text { Acho útil utilizar esta Unidade de Ensino } \\
\text { em aula. }\end{array}$ & & & & & \\
\hline $\begin{array}{l}\text { O uso da Unidade de Ensino me motivou a } \\
\text { aprender. }\end{array}$ & & & & & \\
\hline $\begin{array}{l}\text { Aprendo mais com aulas tradicionais (au- } \\
\text { las apenas expositivas). }\end{array}$ & & & & & \\
\hline $\begin{array}{l}\text { Recomendo que outros professores utili- } \\
\text { zem a Unidade de Ensino. }\end{array}$ & & & & & \\
\hline
\end{tabular}




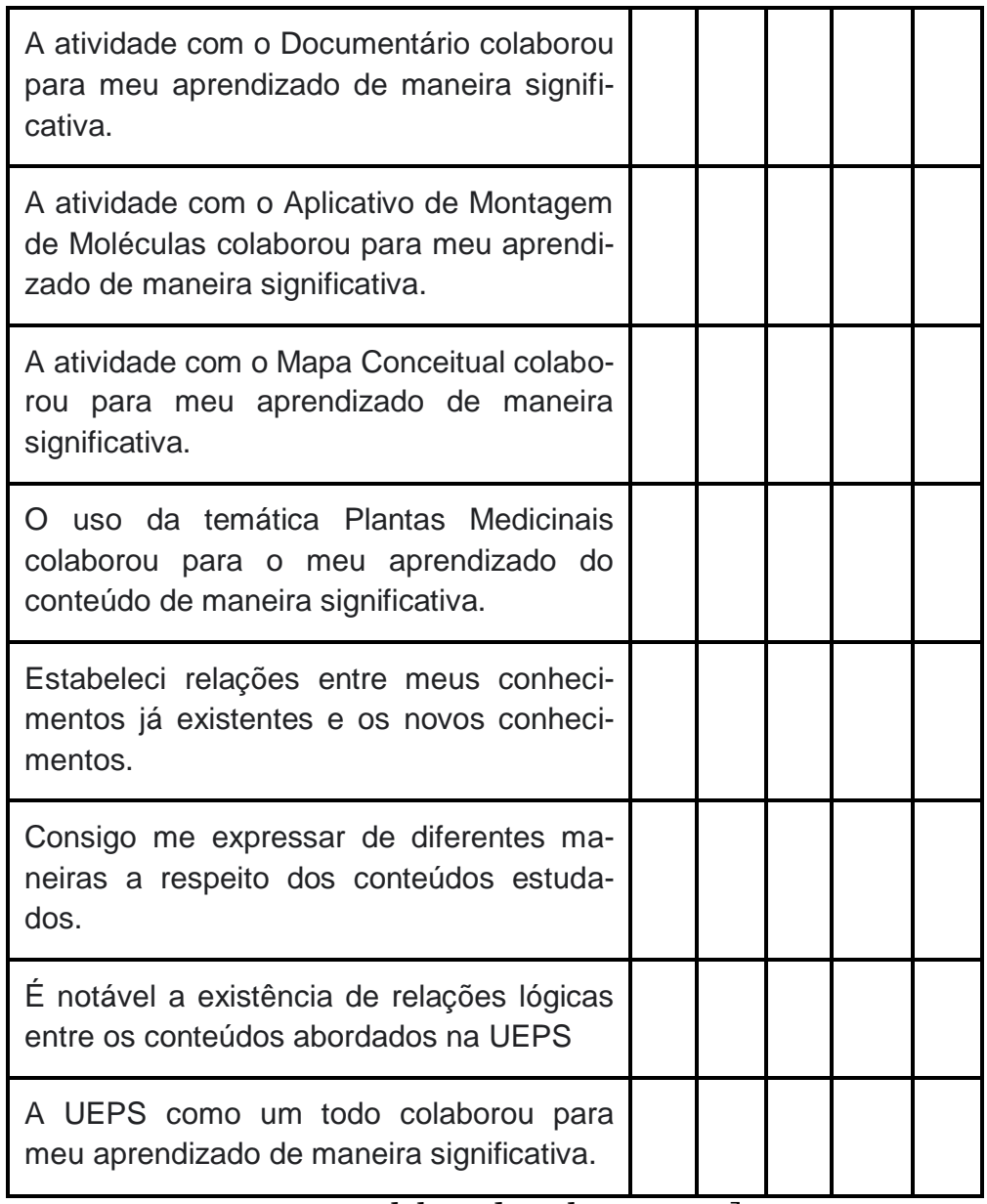

Fonte: Elaborado pelas autoras]

A avaliação da UEPS pelos alunos pode indicar lacunas no trabalho de mediação docente, e possibilita o desenvolvimento autônomo dos alunos, ao proporcionar 
um ambiente onde os mesmos têm a liberdade de se manifestar.

\section{Considerações finais}

Buscamos com esta proposta de UEPS, apresentar possibilidades didáticas para o ensino de estereoquímica a nível médio, seja no ensino presencial ou no remoto. Nossa unidade de ensino segue os moldes das unidades de ensino potencialmente significativas propostas por Moreira (2011). Trilhando uma sequência lógica entre os conteúdos da matéria de ensino, organizados em ordem crescente de complexidade e contando com recursos didáticos potencialmente significativos, que buscam a participação ativa dos alunos e sua motivação para o desenvolvimento das habilidades necessárias no entendimento dos tópicos de estereoisomeria.

A Química Orgânica é uma área da Química onde muitas características e fenômenos são definidos pela organização tridimensional das moléculas. O estudo da Química Orgânica, e especificamente da estereoisomeria em compostos orgânicos, exige do aluno o desenvolvimento de habilidades de visualização tridimensional e de habilidades representacionais, acompanhadas de um raciocínio científico (GRAULICH, 2015).

A estratégia neste trabalho recomenda a busca da 
participação ativa dos alunos, partindo dos conhecimentos prévios dos mesmos na introdução dos conceitos, e com o uso de diferentes ferramentas didáticas na resolução de problemas em três dimensões, como aplicativos e softwares, à exemplo do aplicativo Molecular Constructor, ou do software Chemsketch; propondo ainda ao aluno o desafio de organizar, relacionar e aprofundar os conceitos trabalhados na forma de um mapa conceitual, que também pode ser realizado por meio de ferramentas online como o Cmap Cloud.

Para que a aprendizagem seja significativa para o estudante, devem ser explícitas as relações lógicas entre os subsunçores, conceitos existentes na estrutura cognitiva do aprendiz, e os novos conceitos trabalhados. Estas relações podem ser facilitadas com a contextualização temática, que busca aproximar os conceitos da matéria com elementos da vida do aluno, sendo a utilização de temáticas não somente uma possível conexão entre os conhecimentos prévios e os novos conhecimentos, mas também um elemento motivador na medida em que possibilita a interpretação de questões científicas. Propomos assim essa unidade de ensino alicerçada na relação entre princípios ativos de plantas medicinais e suas características estereoquímicas, procurando suscitar a reflexão a respeito da sociobiodiversidade brasileira, dos saberes populares e sua relação com o conhecimento científico, exemplificando e introduzindo tópicos de isomeria espacial com a proposição de atividades colaborativas. 
Tradicionalmente as estratégias adotadas em situações de ensino se baseiam na exposição e memorização de conceitos. $\mathrm{O}$ conhecimento trabalhado de maneira mecânica tem menores chances de permanecer na estrutura cognitiva do aluno, uma vez que não promove a ancoragem dos novos conhecimentos com os conhecimentos prévios. Nos empenhamos assim na construção de um material instrucional, que se utiliza de estratégias para superar os desafios específicos da estereoisomeria e propõe uma avaliação processual e diversificada.

Empregar uma unidade de ensino potencialmente significativa, partindo de uma temática pertinente, significa romper com o paradigma do professor detentor de saber e do aluno receptor, memorizador e repetidor; incitando a construção de relações não literais e não lineares entre os saberes e seus interlocutores. Trata-se de um desafio, portanto, a mudança de postura, tanto do professor para mediador, quanto do aluno para construtor de sua estrutura cognitiva; processos que terão resultados mais expressivos a longo prazo, quanto mais participativas forem as estratégias. Desafio esse que aumentou com o trabalho remoto, onde propiciar a participação e colaboração dos discentes exige a adoção de novas estratégias. 


\section{Referências}

AQUINO, K. A. da S.; CHIARO, S. de. Uso de Mapas Conceituais: percepções sobre a construção de conhecimentos de estudantes do ensino médio a respeito do tema radioatividade. Ciências \& Cognição, Rio de Janeiro. v. 18, n. 2, p. 158-171, 2013.

AUSUBEL, D. P. Aquisição e retenção de conhecimentos: uma perspectiva cognitiva. Lisboa: Editora Plátano, 2003.

AUSUBEL, D. P.; NOVAK, J. D.; HANESIAN, H. Psicologia Educacional. 2. ed. Rio de Janeiro: Editora Interamericana,1980.

BARREIRO, E. J.; FERREIRA, V. F.; COSTA, P. R. R. Substancias enantiomericamente puras (SEP): a questão dos fármacos quirais. Química Nova,v.20, n.6,1997.

BRASIL. Agência Nacional de Vigilância Sanitária. Formulário de Fitoterápicos da Farmacopeia Brasileira. Brasília: Anvisa, 2011. Disponível em <www.anvisa.gov.br>. Aceso 05 jun. 2019.

CARAMORI, G. F.; OLIVEIRA, T. Aromaticidade - Evolução Histórica do conceito e Critérios Quantitativos. São Paulo: Química Nova, v. 32, n. 7, p.1871-1884, 2009.

CORREIA, P. R. M.; DONNER JR, J. W. A.; INFANTEMALACHIAS, M. E. Mapeamento conceitual como estratégia para romper fronteiras disciplinares: avaliando a importância da isomeria dos compostos orgânicos nos sistemas biológicos. Ciência e Educação (Unesp. Impresso), v. 14, p. 483-495, 2008 
DELIZOICOV, D.; ANGOTTI, J. A.; PERNAMBUCO, M. M. Desafios para o ensino de Ciências. Ensino de Ciências: fundamentos e métodos. São Paulo: Cortez, 2002, p. 31-42.

EVANS, G. G. Stereochemistry in the terminal course. Journal of Chemical Education, v.40, 1963.

FIGUEIREDO, C. S. S.; SILVA et al. Óleo essencial da Canela (Cinamaldeído) e suas aplicações biológicas. Rev. Investig, Bioméd.. São Luis, Maranhão, v. 9, p.192-197, 2017.

FROMM, F. On stereochemistry, Journal of Chemical Education. (Letter) v.1, p. 4322, 1945.

GRAULICH, N. The tip of the iceberg in organic chemistry classes: how do students deal with the invisible?. Chemistry Education Research and Practice, v. 16, n. 1, 9-21, 2015.

HABRAKEN, C. L. Perceptions of chemistry: Why is the common perception of chemistry, the most visual of sciences, so distorted?. Journal of Science Education and Technology, v. 5, n. 3, p. 193-201, 1996.

KOZMA, R. B.; RUSSELL, J. Multimedia and understanding: Expert and novice responses to different representations of chemical phenomena.Journal of research in science teaching, v. 34, n. 9, p. 949-968, 1997.

KRASILCHIK, M. Reformas e realidade: o caso do ensino das ciências. São Paulo em perspectiva, v. 14, n. 1, p. 85-93, 2000.

LIMA, J. A. et al. Avaliação da aprendizagem em Química com uso de mapas conceituais. Revista Thema, Pelotas, v. 14, n. 2, p. $37-49,2017$. 
MCMURRY, J. Química Orgânica. Vol.1. São Paulo: Cengage Learning, 2011.

MCNAUGHT, A. D. The IUPAC Compendium of Chemical Terminology (2nd ed.). Blackwell Scientific Publications, 2019.

MONTEIRO, I. N. Composição química e avaliação da atividade carrapaticida do óleo essencial de Cinnamomun zeylanicum NO CONTROLE DE Rhipicephalus microplus. 2013. Dissertação (Mestrado em Química) - Programa de Pósgraduação em Química, Universidade Federal do Maranhão, São Luís, 2013.

MORAIS, S. M. et al. Ação antioxidante de chás e condimentos de grande consumo no Brasil. Brazilian Journal of Pharmacognosy, Curitiba, v. 19(1B), p. 315-320, jan./mar., 2009.

MOREIRA, M. A. Mapas Conceituais e Aprendizagem Significativa. Revista Galáico Portuguesa de Sócio Pedagogia e Sociolinguística. Pontevedra/Galícia/Espanha e Braga/Portugal, n. 23 a $28,87-95,1988$.

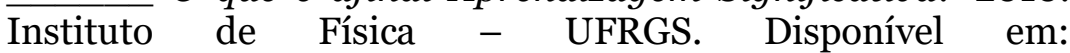
$<$ http://www.if.ufrgs.br/ moreira/oqueeafinal.pdf>. Acesso em: 02 ago. 2019.

MOREIRA, M. A. Unidades de enseñanza potencialmente significativas - UEPS. Aprendizagem Significativa em Revista, v. 1, n. 2, p. 43-63, 2011.

OLIVEIRA, H. M. B. F. Avaliação das atividades antifúngica, antioxidante e citotóxica dos monoterpenos (r)-(+)-citronelal, (s)-(-)-citronelal, 7-hidroxicitronelal. 2016. Tese (Doutorado em Produtos Naturais e Sintéticos Bioativos) - Programa de 
Pós-Graduação em Produtos Naturais e Sintéticos Bioativos, Universidade Federal da Paraíba, João Pessoa, 2016.

PAZINI, A.; DUPONT, J. Isomerização Seletiva do Estragol para o trans-anetol em Líquidos Iônicos Conselho Nacional de Desenvolvimento Científico e Tecnológico Laboratory of Molecular Catalysis (LMC), Instituto de Química, UFRGS. 2013.

PINTO, C. G. Desenvolvimento, caracterização, estudos de estabilidade, genotoxicidade, citotoxicidade e ecotoxicidade de sistemas nanoestruturados contendo óleo essencial de gengibre ou trans-anetol. 2018. Tese (Doutorado em Nanociências) - Programa de Pós-Graduação em Nanociências, Ufn, Santa Maria, 2018.

PINTO, P. R. Estudo da atividade antibacteriana da Carvona $e$ seus derivados. 2014. Dissertação (Mestrado em Química Industrial) - (Programa de Pós-Graduação em Química Industrial), Universidade da Beira Interior, Covilha, 2014.

RAUPP, D. T. Alfabetização tridimensional, contextualizada e histórica no campo conceitual da estereoquímica. 2015. Tese (Doutorado em Educação em Ciências). Programa de Pósgraduação em Educação e Ciências: Química da vida e saúde, Instituto de Ciências Básicas da Saúde, Universidade Federal do Rio Grande do Sul, Porto Alegre, 2015.

RAUPP, D. T.; PROCHNOW, T. R.; DEL PINO, J. C. História e contextualização no ensino de estereoquímica: uma proposta de abordagem para o ensino médio. Revista Contexto \& Educação, v. 35, n. 112, p. 432-455, 2020 a.

ROCKENBACH, L. C. et al. Estereoquímica em plantas medicinais: uma proposta de unidade de ensino potencialmente significativa para o ensino médio. REPPE-Revista de Produtos 
Educacionais e Pesquisas em Ensino, v. 4, n. 1, p. 49-75, 2020b.

SCHITTLER, D.; MOREIRA, M. A. Laser de rubi: uma abordagem baseada em unidades de ensino potencialmente significativas (UEPS). Latin-American Journal of Physics Education. v. 8 , n. 2, p. 263 - 273, jun., 2014

SHINE, H. J. Aids in teaching stereochemistry: Plastic sheets for plane projection diagrams. Journal of Chemical Education, v. 34, n. 7, p. 355, 1957.

SILVA, G. do B. Isolamento, caracterização, quantificação $e$ avaliação da pureza enantiomérica de linalol, carvona e limoneno em óleos essenciais de espécies aromáticas. 2011. Dissertação (Mestrado em Química). Programa de Pósgraduação em Química, Universidade Federal de Sergipe, 2011.

SIMÕES, C. M. O.; SCHENKEL, E. P. A pesquisa e a produção brasileira de medicamentos a partir de plantas medicinais: a necessária interação da indústria com a academia. Revista brasileira de farmacognosia, v. 12, n. 1, p. 35- 40, 2002, p. 21.

SOUZA, C. M. Pereira et al. Utilização de plantas medicinais com atividade antimicrobiana por usuários do serviço público de saúde em Campina Grande - Paraíba. Revista Brasileira de Plantas Medicinais, v. 15, n. 2, p. 188-193, 2013.

TAVARES, R. Aprendizagem significativa. Revista conceitos, v. 55, n. 10, 2004.

WU, H. K.; SHAH, P. Exploring visuospatial thinking in chemistry learning. Science Education, v. 88, n. 3, p. 465-492, 2004. 